\title{
Completely thoracoscopic bilateral pulmonary vein isolation and left atrial appendage exclusion for atrial fibrillation
}

\author{
A. Yilmaz, B. P. Van Putte, and W. J. Van Boven, Nieuwegein, The Netherlands
}

$\mathrm{W}$

e describe a minimally invasive surgical technique involving completely thoracoscopic bilateral pulmonary vein isolation and left atrial appendage exclusion for the treatment of atrial fibrillation.

In January and February 2007, we performed nine totally thoracoscopic bilateral pulmonary vein isolations and left atrial appendage exclusions. All patients (mean age $59.7 \pm 8.8$ years) had paroxysmal atrial fibrillation. Four patients had a history of repeated unsuccessful percutaneous catheter procedures. Magnetic resonance imaging of the pulmonary veins showed a left common trunk pulmonary vein in one patient whereas normal anatomy was observed in the other patients.

All patients were operated on under general anesthesia in the supine position with both arms slightly flexed along the body. A slight tilt of the operating table without repositioning of the patient was sufficient for adequate exposure on both sides. Furthermore, in case of an urgent sternotomy, repositioning of the patient was not necessary. Three thoracoports were introduced on each side, the first on the midaxillary line and a second $5 \mathrm{~cm}$ anteriorly through the fourth intercostal space. The third port was inserted caudally of the first port through the sixth intercostal space (Figure 1). Pulmonary vein isolation was accomplished with the Lumitip dissector and the bipolar Isolator Endo ablation clamp (AtriCure, Inc, West Chester, Ohio). Isolation was confirmed with high-frequency stimulation on the pulmonary veins in case of sinus rhythm. Additional ablation was performed if isolation was incomplete. The Isolator multifunctional pen (Atricure) was used for disruption of ganglionic plexi if these were present. The presence of ganglionic plexi was determined by stimulation of the proximal part of the pulmonary veins with a high-frequency pacemaker. The left atrial appendage was excluded with a PDS Endoloop (Ethicon, Amersfoort, The Netherlands). Patients were extubated in the operation room.

All patients received warfarin sodium (Coumadin) anticoagulation therapy for 6 months. Warfarin was stopped if sinus rhythm was confirmed by 24-hour Holter registration. Warfarin was continued in one patient because of a history of a cerebrovascular accident.

From the Department of Cardiothoracic Surgery, St Antonius Hospital, Nieuwegein, The Netherlands.

Received for publication July 30, 2007; revisions received Dec 28, 2007; accepted for publication Jan 29, 2008.

Address for reprints: A. Yilmaz, cardio-thoracic surgeon, Department of Cardiothoracic Surgery, St Antonius Hospital, Koekoekslaan 1, Nieuwegein, The Netherlands (E-mail: a.yilmaz@antonius.net).

J Thorac Cardiovasc Surg 2008;136:521-22

0022-5223/ $\$ 34.00$

Copyright (C) 2008 by The American Association for Thoracic Surgery doi:10.1016/j.jtcvs.2008.01.035

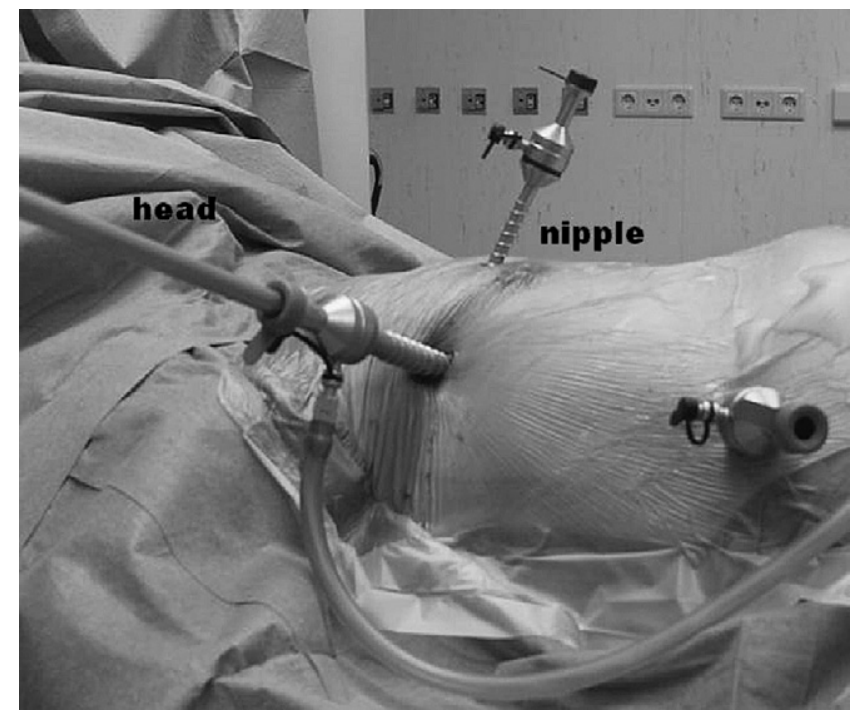

Figure 1. Three thoracoports were introduced on each side, the first on the midaxillary line and a second $5 \mathrm{~cm}$ anteriorly through the fourth intercostal space. The third port was inserted between the two ports through the sixth intercostal space.

All procedures were performed without technical problems. Mean operation time was 134 minutes (range: 106-197 minutes). Blood loss was minimal in all cases. Mean hospital stay was 7 days (range: 4-9 days). Two patients had unilateral paralysis of the diaphram but no further complications were observed. After a mean follow-up of 284 days (range: $244-328$ days) $78 \%$ (2/9) of all patients were in sinus rhythm (Table 1).

\section{Discussion}

Since 2004, a few papers have been published on video-assisted pulmonary vein isolation and atrial appendage exclusion as a new surgical technique for the treatment of atrial fibrillation. ${ }^{1,2}$ On the basis of the limited number of patients, freedom from atrial fibrillation was described between $80 \%$ and $91 \%$ after 6 months postoperatively compared with $96 \%$ after the Cox maze III procedure. ${ }^{3,4}$

In contrast to video-assisted pulmonary vein isolation, no minithoracotomy or extra incisions are necessary in completely thoracoscopic bilateral pulmonary vein isolation, maybe resulting in less pain and morbidity and quicker recovery. Exposure of the pulmonary veins is identical in both techniques.

Furthermore, completely thoracoscopic bilateral pulmonary vein isolation and left atrial appendage exclusion could be an attractive and maybe less complicated alternative than percutaneous pulmonary vein isolation. In contrast to percutaneous isolation, complete 
TABLE 1. Preoperative and postoperative patient characteristics

\begin{tabular}{|c|c|c|c|c|c|c|c|c|c|c|}
\hline \multirow[b]{2}{*}{ Patient } & \multicolumn{5}{|c|}{ Preoperative characteristics } & \multicolumn{5}{|c|}{ Postoperative characteristics } \\
\hline & $\begin{array}{l}\text { Catheter } \\
\text { ablation } \\
\text { in history }\end{array}$ & $\begin{array}{l}\text { Age } \\
(y)\end{array}$ & $\begin{array}{l}\text { Duration } \\
\text { of } A F(\mathbf{m o})\end{array}$ & $\begin{array}{c}\text { Atrial } \\
\text { size }(\mathrm{mm})\end{array}$ & $\begin{array}{l}\text { Discharge } \\
\text { (d) }\end{array}$ & Holter & Warfarin & $\begin{array}{l}\text { Antiarrhythmic } \\
\text { drugs }\end{array}$ & $\begin{array}{c}\text { Holter } \\
\text { follow-up (d) }\end{array}$ & Complication \\
\hline 1 & Yes & 61 & 72 & 50 & 5 & SR & No & No & 328 & No \\
\hline 2 & No & 65 & 60 & 43 & 7 & $\mathrm{AF}$ & Yes & Yes & 313 & No \\
\hline 3 & Yes & 56 & 228 & 55 & 8 & SR & No & No & 267 & $\begin{array}{l}\text { Paralysis of } \\
\text { hemidiaphram }\end{array}$ \\
\hline 4 & Yes & 39 & 156 & NA & 4 & SR & Yes & Yes & 312 & No \\
\hline 5 & No & 57 & 192 & 64 & 8 & $\mathrm{AF}$ & Yes & Yes & 301 & No \\
\hline 6 & No & 62 & 36 & NA & 9 & SR & No & No & 255 & $\begin{array}{l}\text { Paralysis of } \\
\text { hemidiaphram }\end{array}$ \\
\hline 7 & No & 59 & 36 & NA & 7 & SR & No & No & 246 & No \\
\hline 8 & Yes & 63 & 144 & 48 & 7 & SR & No & No & 284 & No \\
\hline 9 & No & 44 & 12 & 69 & 4 & SR & No & No & 244 & No \\
\hline Mean & $44 \%$ & $60 \pm 9$ & $72 \pm 72$ & $50 \pm 12$ & $7 \pm 2$ & $78 \%$ & $33 \%$ & $33 \%$ & $284 \pm 32$ & $22 \%$ \\
\hline
\end{tabular}

Warfarin and antiarrhythmic drug usage was noted for the day after Holter follow-up. NA, Not available; $A F$, atrial flutter; $S R$, sinus rhythm.

isolation is easily achieved in all patients under direct vision and is not time consuming after a short learning curve.

In conclusion, this is the first series of completely thoracoscopic bilateral pulmonary vein isolations and left atrial appendage exclusions for the treatment of atrial fibrillation, resulting in an excellent short-term outcome. This minimally invasive approach may contribute to a short-stay concept in the near future.

\section{References}

1. Wolf RK, Schneeberger EW, Osterday R, Miller D, Merrill W, Flege B Jr., et al. Video-assisted bilateral pulmonary vein isolation and left atrial appendage exclusion for atrial fibrillation. J Thorac Cardiovasc Surg. 2005; 130:797-802.

2. Sagbas E, Akpinar B, Sanisoglu I, Caynak B, Tamtekin B, Oral K, et al. Video-assisted bilateral epicardial pulmonary vein isolation for the treatment of lone atrial fibrillation. Ann Thorac Surg. 2007;83:1724-30.

3. Mokadam NA, McCarthy PM, Gillinov AM, Ryan WH, Moon MR, Mack MJ, et al. A prospective multicenter trial of bipolar radiofrequency ablation for atrial fibrillation: early results. Ann Thorac Surg. 2004;78: 1665-70.

4. Prasad SM, Maniar HS, Camillo J, Schuessler RB, Boineau BP, Sundt TM, et al. The Cox maze III procedure for atrial fibrillation: long-term efficacy in patients undergoing lone versus concomitant procedures. J Thorac Cardiovasc Surg. 2003;126:1822-7.

\section{Dumbbell-shaped mediastinal neurogenic tumor forming a string-of-beads structure}

Ryuichi Suemitsu, MD, PhD, Hironori Matsuzawa, MD, Masafumi Yamaguchi, MD, PhD, and Sadanori Takeo, MD, PhD, Fukuoka, Japan

From the Department of Thoracic Surgery, Clinical Research Institute, National Hospital Organization, Kyushu Medical Center, Fukuoka, Japan.

Received for publication Aug 1, 2007; accepted for publication Aug 30, 2007.

Address for reprints: Ryuichi Suemitsu, MD, PhD, Department of Thoracic Surgery, National Hospital Organization, Kyushu Medical Center, Jigyohama 1-chome, 8-1, Chuo-ku, Fukuoka City, Japan 810-8563 (E-mail: suemitsu@qmed.hosp.go.jp).

J Thorac Cardiovasc Surg 2008;136:522-3

$0022-5223 / \$ 34.00$

Copyright $\odot 2008$ by The American Association for Thoracic Surgery doi:10.1016/j.jtcvs.2007.08.082
A 38-year-old man had an abnormal shadow in the left upper lung field of a chest radiograph taken by his family physician. A chest computed tomographic scan showed a homogeneous tumor $10 \mathrm{~cm}$ in diameter with a string of 4 beads along the fourth intercostal space, originating from the posterior mediastinum and projecting from the spinal canal between the fourth and fifth thoracic vertebrae (Th4 and Th5). Magnetic resonance imaging revealed a thoracic dumbbell-shaped tumor producing spinal cord compression in the extradural space (Figure 1). Serum chemistry and blood counts were within normal limits and the patient had no paralytic symptoms or café-au-lait spots.

The operative findings were as follows. Under general anesthesia, the patient was intubated with a double-lumen endotracheal 